Elsevier required licence: (C) <2017>. This manuscript version is made available under the CC-BY-NC-ND 4.0 license http://creativecommons.org/licenses/by-nc-nd/4.0/ 


\title{
The role of project portfolio management in fostering both \\ deliberate and emergent strategy
}

\author{
Julian Kopmann \\ Bombardier Transportation \\ Schöneberger Ufer 1, 10785 Berlin, Germany \\ julian.kopmann@rail.bombardier.com
}

\begin{abstract}
Alexander Kock*
Technische Universität Darmstadt, Chair for Technology and Innovation Management

Hochschulstraße 1, 64289 Darmstadt, Germany kock@tim.tu-darmstadt.de, phone: +49-6151-1624351
\end{abstract}

\author{
Catherine P Killen \\ School of the Built Environment, University of Technology Sydney \\ P O Box 123, Broadway NSW 2007, AUSTRALIA \\ catherine.killen@uts.edu.au \\ Hans Georg Gemünden \\ Handelshoyskolen BI, Department of Leadership \& Organization \\ Oslo, Akershus, Norway \\ hans.gemuenden@tim.tu-berlin.de
}

* corresponding author

\begin{abstract}
Formal strategy processes have been shown to be insufficient in shaping strategy, particularly in turbulent environments. Emerging strategies that constitute independently from deliberate top-down strategy processes are important for organizational adaptability. This study explores strategic control mechanisms at the project portfolio level and their influence on emergent and deliberate strategies. Based on a sample of 182 firms, we show that both deliberate and emerging strategies positively influence project portfolio success, complementing each other. In turbulent environments, the relevance of deliberate strategy implementation decreases. Strategic control activities not only fosters the implementation of
\end{abstract}


intended strategies, but also discloses strategic opportunities by unveiling emerging patterns. Furthermore, we find that deliberate strategy implementation and emerging strategy recognition mediate the performance impact of strategic control. Our findings suggest that strategic control at the project portfolio level has an important role to play in the purposeful management of emergent strategies.

Keywords: Project Portfolio Management, Deliberate Strategy, Emergent Strategy, Strategic Control, Strategy Implementation 


\section{The role of project portfolio management in fostering both \\ deliberate and emergent strategy}

\section{Introduction}

Almost 40 years since Mintzberg introduced the concept of emergent strategy (Mintzberg, 1978; Mintzberg and Waters, 1985), the impetus to understand the complexity of strategy processes, both deliberate and emergent, is strong and growing (Vaara and Whittington, 2012). Acting alone, formal and rigid strategy processes have been shown to be insufficient in shaping strategy in response to change (McKiernan and Morris, 1994; Parnell et al., 2012). In today's volatile and unforgiving competitive environment, it might be the emergent strategic processes that are particularly relevant for organizational adaptability and survival (Chari et al., 2014; Hamel, 2009; Thomas and D'Aveni, 2009; Whittington et al., 2016). Emergent strategies are realized in absence of or despite formal strategic intention and by nature fall outside traditional strategy processes; this makes it difficult to control their influence and has prompted exploration of alternate methods to manage 'planned emergence' (Grant, 2003; Levina and $\mathrm{Su}, 2008$ ). This study explores how strategic control mechanisms implemented at the portfolio level can influence organizational performance by not only measuring performance, but also providing impetus and direction for change and emergence in strategic processes (Bititci et al., 2012; Thomas and Ambrosini, 2015).

The bulk of strategic management research focuses on deliberate strategies and strategy content and formulation, while strategy implementation is sometimes portrayed as an autonomous activity and is not subjected to much scrutiny (Bower and Gilbert, 2005; Hrebiniak, 2006; Hutzschenreuter and Kleindienst, 2006; Raes et al., 2011). However, according to Mankins and Steele (2005), firms realize only $63 \%$ of their strategies' potential value, and Johnson (2004) reports that $66 \%$ of corporate strategy is never implemented. Despite warnings that it is more difficult to make strategy work than to develop it (Hrebiniak, 
2006), approaches to implementing strategy tend to take a narrow view and look for the best way to implement the deliberate strategy, rather than to consider other possibilities such as the role of emergence (Meskendahl, 2010; Morgan et al., 2008; Unger et al., 2012). The limitations of deliberate strategy implementation are highlighted in a review by Hutzschenreuter and Kleindienst (2006); of 202 empirical articles on strategy processes identified in the review, 35 analyzed the impact of strategy process characteristics on corporate performance and less than half (16) of these studies showed a positive influence from deliberate strategies. Only two of the articles analyzed in the review explored the performance impact of emergent strategies, and the findings were contradictory.

Nevertheless, there is a body of empirical research that describes how emergent strategy arises from resource allocation (Burgelman, 1994; Noda and Bower, 1996), autonomous strategic behavior (Burgelman, 1983; Mirabeau and Maguire, 2014), and is fostered by interactive strategic control systems (Osborn, 1998; van Veen-Dirks and Wijn, 2002). The new paradigm of 'planned emergence' constitutes a shift from the traditional perception of strategic planning as a resource deployment process towards viewing 'strategy as aspirations and performance goals' (Grant, 2003). 'Planned emergence' promotes differences in attention to timeframe and level when compared with traditional strategic planning; 'planned emergence' brings strategic vision to the present, recognizing micro-level practices whereas traditional strategic planning focuses on the future and on macro-level analysis (e Cunha et al., 2006). In an analysis of major oil companies, Grant (2003) found that these new 'planned emergence' processes are characterized by shorter planning horizons, greater flexibility, and an increased emphasis on performance targets that primarily aim at controlling and coordinating the different parts of the business (see also Kim et al., 2014; Meissner, 2014). In addition, a wider dialogue in management research aims to better understand the success of strategy processes and the influence of context, communication, and informal processes and 
controls (Hodgkinson et al., 2006; Meissner, 2014; Regner, 2003; Thomas and Ambrosini, 2015).

We address the need to further explore activities through which strategies emerge (Vaara and Whittington, 2012) by focusing on the role of project portfolio management in strategy implementation. Literature suggests that emergent as well as deliberate (intended) strategies are realized through a portfolio of strategic initiatives (either induced or autonomous) that compete for scarce resources (Burgelman, 1991; Noda and Bower, 1996; Shenhar et al., 2001). These strategic initiatives are often implemented through a portfolio of projects and their strategic alignment is best managed from a project portfolio perspective (Morris and Jamieson, 2005; Shenhar et al., 2001). Management activities at this level can play a decisive role in implementing both emergent and deliberate strategies.

We have selected the project portfolio perspective for this study because project portfolio management, which is responsible for the prioritization, selection, and termination of projects, acts as a bridge between strategy formulation and its implementation (Meskendahl, 2010). The management of a project portfolio encompasses projects that are initiated through the organization's formal and cascaded strategy process as well as projects that evolve in an 'emergent' fashion and may not be well aligned to the existing strategy (Mirabeau and Maguire, 2014). Thus, project portfolio management not only frames the process of translating a corporate strategy into a project roadmap for implementation, but also provides the oversight of the project landscape that comprises the grassroots of emergent strategies. To better understand the relationship between strategy and project portfolio management, we examine the application of strategic control activities, in particular those that have been identified as levers for exploiting emergent strategies, enabling response to change, and reversing the traditional 'top-down' relationship between strategy formulation and implementation (Osborn, 1998; Simons, 2013). 
Our research contributes to the discussion about the roles of strategy formulation and implementation and the effects of emerging elements under changing environmental conditions (Mintzberg, 1990). We examine management activities at the project portfolio level, specifically investigating the application of strategic control mechanisms in the nexus between deliberate and emergent strategies and the resultant effect on realized strategy and success.

The research is guided by the following research questions: What is the relationship between deliberate and emergent strategies and project portfolio success? How are these relationships moderated by environmental turbulence? What role does strategic control play in the formation of deliberate and emergent strategies? What is the relationship between strategic control and project portfolio success?

We address these research questions through a conceptual framework that relates strategic control to both the implementation of deliberate strategies and the recognition of emerging strategies and subsequently project portfolio success. The framework is empirically tested on a dual-informant cross-industry survey of 182 medium-sized and large firms. This study contributes to the literature in several ways. First, we reveal how management activities at the project portfolio level not only foster the implementation of intended strategies but also disclose strategic opportunities by unveiling emerging patterns. We observe a complementary effect between deliberate strategy implementation and emerging strategy recognition. To the best of our knowledge, there is no empirical study, which has tested the simultaneous performance influence or interaction of deliberate and emerging strategy implementation. Second, we find that strategic control positively contributes to the effectiveness of deliberate strategy implementation and emerging strategy recognition., which mediate its influence on project portfolio success. Finally, we also investigate the moderating impact of environmental turbulence and find that deliberate strategy implementation has a weaker relationship with 
success under high turbulence. The findings provide guidance for management practice by highlighting the role of strategic control in strategy implementation and 'planned emergence'.

\section{Theoretical background}

\subsection{Strategy formation and emerging strategies}

An organization's strategy determines its objectives, purposes and goals, and defines the plans to achieve them while dealing with the question how to achieve and sustain a competitive advantage (Teece et al., 1997). In the literature, the strategy formation process is typically divided into two parts: strategy formulation refers to goal-setting and planning of strategies while strategy implementation concerns the realization of the strategy. Mintzberg $(1978,1990)$ criticizes the dichotomy of strategy formulation and implementation and argues that this dichotomy is based on the assumptions that the 'formulator is fully informed' and the 'environment is sufficiently stable' (Mintzberg, 1978, p. 964). If only one condition is not met, strategy formation becomes a learning process that requires an adaptive approach rather than a planning approach. In the same vein, Johnson et al. (2008) argue that in practice, due to unanticipated opportunities or threats, the strategies that are actually pursued are typically a mixture of both intended and adapted strategy.

Mintzberg and Waters (1985) explored the discrepancy between the strategic plans and what the organization actually did and revealed two types of strategies: deliberate strategies, which are realized as planned, and emergent strategies, which appear despite or in the absence of formal planning or intentions. In a perfectly deliberate strategy three conditions must be met: (1) strategic intentions must be precise and fully articulated (2) the commitment to implement the strategy must be shared by all actors of an organization (3) the strategy must not be affected by external forces (either the environment must be absolutely predictable or under control). In reality, these conditions do not exist and implementation of a perfectly deliberate strategy is highly unlikely. On the other side, emergent strategies are not planned; 
they are the patterns of action that occur independently of any formal planning or intention. Therefore, a purely emergent strategy requires the absence of any formal intention, which is also highly unlikely.

In reality strategies are enacted through a combination of both emergent and deliberate mechanisms. From a project and project portfolio management perspective, the two-way relationship between strategy and projects has been observed in several studies (see for example Killen and Hunt, 2010; Poskela et al., 2005; Poskela and Martinsuo, 2009) and project portfolio management has been highlighted as a dynamic capability due to the advantages offered in enabling organizational response to change (Killen and Hunt, 2010; Killen et al., 2012; Kock and Gemünden, 2016; Petit, 2012; Petit and Hobbs, 2010). Mintzberg and Waters (1985, p. 271) conclude that strategy formation 'walks on two feet, one deliberate, the other emergent'. The review from Kürschner and Günther (2012) documents that both, deliberate and emergent strategies contribute to better performance. Similarly, Hart (1992) proposes that neither a sheer top-down style (command mode, directing) nor a pure bottom-up style (generative mode, responding) will lead to success, and that a mixture of both is required. To do both, the management needs to simultaneously set direction to realize intended strategies and be responsive to emergent elements. Strategic controls can play a role in balancing formality and flexibility in strategy processes (Atkinson, 2006; Goold and Quinn, 1990) and in enabling response to emergent strategy elements (Mintzberg and Waters, 1985).

\subsection{Strategic control}

Strategic control activities enable organizations to monitor and manage strategy processes. Simons (2013) distinguishes between two types of strategic control systems: diagnostic controls and interactive controls. While diagnostic controls can be applied to motivate, 
monitor, and reward the achievement of strategic goals, interactive control systems include feedback mechanisms and therefore have the ability to facilitate organizational learning and the emergent elements such as new ideas or new strategic directions. Consequently, in order to influence 'emerging patterns of actions', Simons recommends using interactive controls that focus on addressing uncertainties that could affect the basis of competitive advantage. Other authors describe interactive control as a 'means for surfacing and acting upon emerging strategies' (Osborn, 1998, p. 488) that provides 'a framework for a more incremental and 'emergent' approach to strategy formulation' (van Veen-Dirks and Wijn, 2002, p. 409), however it is important to note that interactive controls are not solely focused on emergent elements. Taking a wider view, strategic controls contribute to performance measurement capability while also enabling organizations to manage and improve organizational performance (Bititci et al., 2012).

Schreyögg and Steinmann's (1987) conceptualization of interactive strategic controls consists of three aspects: Premise control refers to the continuous verification of planning assumptions during strategy formulation and implementation. Implementation control scrutinizes the currently implemented and pursued strategic direction in contrast to traditional controls that monitor whether strategy implementation is proceeding according to plan. Strategic surveillance takes a less focused view and scans both the internal and external environment of the organization in order to identify 'unforeseeable or previously undetected critical events' (Schreyögg and Steinmann, 1987, p. 97). These aspects control both the expected and unexpected and dynamic aspects of strategy implementation in what Schreyögg and Kliesch-Eberl (2007) later call a dual process approach. In this way the strategic control function can impact strategy formulation and implementation at all stages (Band and Scanlan, 1995; Goold and Quinn, 1990; Preble, 1992; Schreyögg and Steinmann, 1987). 
Schreyögg and Steinmann's (1987) strategic control concept includes a 'feed-forward' aspect where the shortcomings of strategic planning can be rectified. In contrast to feedback controls that take a post-action approach, the feed-forward model enables strategic management to monitor input variables from the internal and external environment, take account of ambiguity and complexity, and anticipate their effect on the intended strategy (Band and Scanlan, 1995; Preble, 1992). This differs from traditional interactive controls by including actions for reformulation of strategy (Muralidharan, 1997) making it a powerful tool for the management of emergent strategies. However, there is a danger of administrative overload in highly turbulent environments; in such environments a looser level of strategic control is recommended (Goold and Quinn, 1990).

In this paper, we connect the concept of strategic control at the project portfolio management level with the discussion on deliberate and emergent strategies and argue that implementing such controls at the portfolio level can enable a firm to better implement deliberate strategies and foster emergent strategies.

\subsection{Strategy implementation and project portfolio success}

Project portfolio management is a strategic management function that provides a bridge between strategy formulation and its implementation (Meskendahl, 2010). The sum of project investments determines the organization's future in terms of shaping its structure, processes and products. Therefore, the organization's portfolio of projects represents the actual pursued strategy. Three phases for project portfolio management are described in the literature (Jonas et al., 2013): 1) the prioritization and selection of projects (Archer and Ghasemzadeh, 2004), 2) resource allocation to and across projects (Engwall and Jerbrant, 2003; Killen et al., 2008), and 3) portfolio steering (i.e. the re-prioritization or termination of projects, re-allocation of resources, exploitation of synergies) (Blichfeldt and Eskerod, 2008; Blomquist and Müller, 
2006; Kock and Gemünden, 2016; Unger et al., 2012). Through these processes, portfolio management implements the business strategy through coordinating decision-making about project investments, balancing risk and resources and maximizing the value of the project portfolio (Cooper et al., 2001; Jonas et al., 2013; Voss and Kock, 2013).

Building on previous research (Kopmann et al., 2015), this study defines project portfolio success as a second-order construct with five dimensions: strategic implementation success, future preparedness, portfolio balance, usage of synergies, and average product success. Strategic implementation success is defined by the strategic fit of the project portfolio (Meskendahl, 2010) and the implementation success of the strategy as perceived by top management. Future preparedness reflects the long-term perspective on portfolio success and describes the organization's preparedness for the future in terms of technological assets and competences (Shenhar et al., 2001). It evaluates the long-term benefits offered by a project portfolio (i.e. creation of new markets and development of new technologies and capabilities) and by that is a measure for the quality of the strategy (Voss and Kock, 2013). Portfolio balance concerns the equilibrium of risks, long- and short-term opportunities and the steady utilization of resources within the project portfolio's execution (Killen et al., 2008; Teller et al., 2012). Average product success is measured by the commercial success of project outcomes, which determine in their entirety the quality and success of the strategy implementation (Kock et al., 2015; Kock et al., 2016). Synergy exploitation represents the added value that emerges from dedicated portfolio management, over and above contributions from individual projects, through capitalizing on interdependencies and avoiding redundancies (Meskendahl, 2010).

These five dimensions build an established construct of project portfolio success that reflects the three aspects of strategy formation: the alignment with the intended strategy (strategic implementation success), the realization of single strategic initiatives through 
projects (average product success and synergy exploitation) and the quality of the currently pursued strategy (portfolio balance and future preparedness). While the first aspect refers primarily to deliberate strategies, the latter two incorporate considerations related to both deliberate and emergent strategy. Bringing these aspects together, the project portfolio success construct provides a comprehensive measure to reflect the success of both the deliberate and the emergent strategy.

\section{Conceptual Framework and Hypotheses}

Figure 1 summarizes our conceptual framework relating strategic control, portfolio management, and project portfolio success in the nexus of deliberate and emerging strategies. We propose that strategic control at the portfolio level contributes to project portfolio success by fostering strategy formation. This relationship is mediated by two management mechanisms: Deliberate strategy implementation and emerging strategy recognition.

Deliberate strategy implementation describes the process of purposefully cascading the formulated corporate strategy to project level in a top-down manner. This process aims at the realization of intended strategies and can be assigned to the 'planned' strategy type (see Mintzberg and Waters, 1985, p. 270). Emerging strategy recognition describes the process to disclose emerging patterns in a project portfolio and to inform the strategy formulation process. This process aims at the creation of awareness for emergent strategies and enable the organization to purposefully cope with emergence. It can be assigned to the less deliberate strategy types such as the 'process' or 'umbrella' type (see Mintzberg and Waters, 1985, p. 270). Both are argued to be positively related to project portfolio success; and we argue that they complement each other in their performance effect. Furthermore, we consider the effect of external turbulence and hypothesize a moderating effect of this environmental context on the relationship with project portfolio success. 


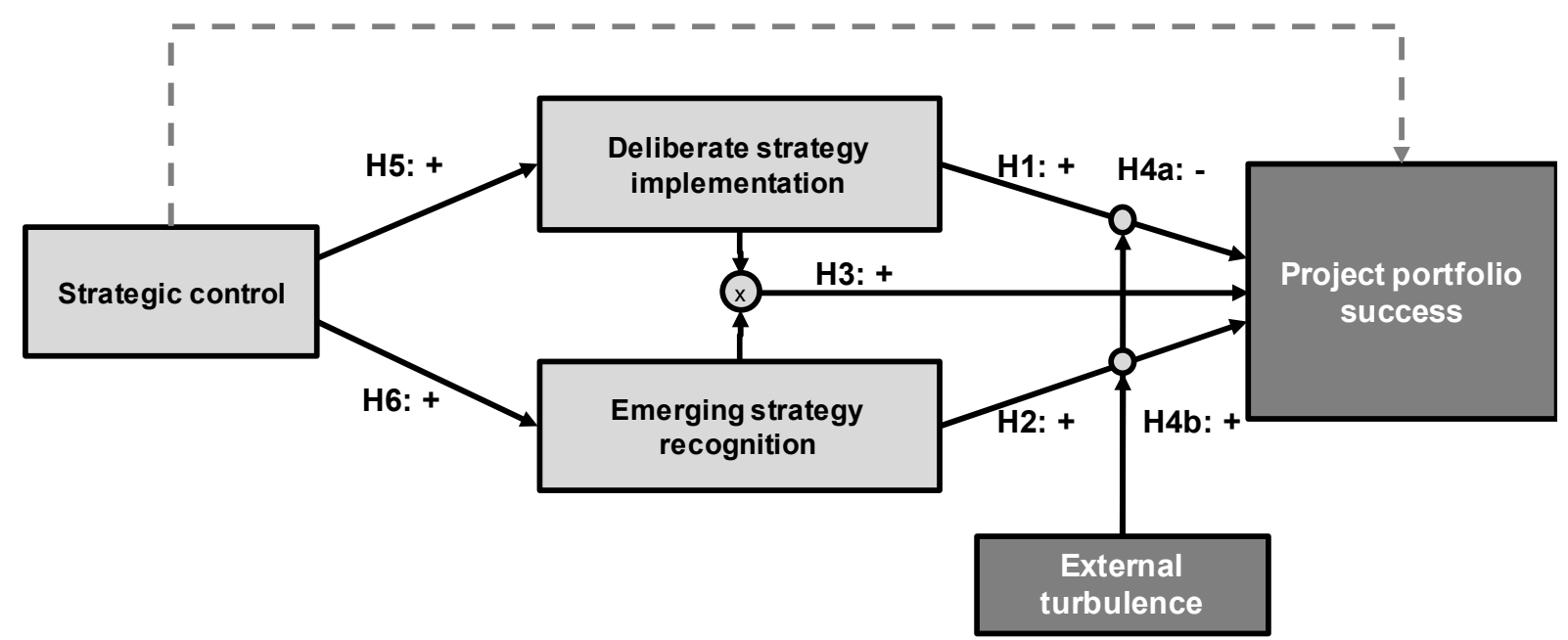

Figure 1. Conceptual framework on strategic control and project portfolio success.

\subsection{Deliberate strategy implementation and project portfolio success}

In organizations where projects and programs form the building blocks for strategy implementation, the project portfolio in its entirety represents an organization's strategy (Benko and McFarlan, 2003; Morgan et al., 2008) and determines its future situation (Cooper et al., 1999). Research on project portfolio management from a strategic perspective repeatedly emphasizes the importance of the prioritization and selection phase (Archer and Ghasemzadeh, 2004; Blichfeldt and Eskerod, 2008; Dietrich and Lehtonen, 2005; Englund and Graham, 1999; Müller et al., 2008).

The top-down 'cascade' perspective posits that projects are prioritized and selected to align the portfolio with the organization's strategic objectives (Morris and Jamieson, 2005). This perspective focuses on the realization of deliberate strategies and does not consider the emergent aspect of strategies. We argue that this deliberate strategy implementation, defined as the alignment of the project portfolio with the intended strategy by linking portfolio planning to the strategic planning process, will be positively related to project portfolio success. 
Hypothesis 1: Deliberate strategy implementation is positively related to project portfolio success.

\subsection{Emerging strategy recognition and project portfolio success}

Extant research shows that project portfolio management in practice is not exclusively a rigid and formal process that is characterized by a cascaded top-down approach. Several studies highlight that focusing only on the realization of deliberate strategies may hinder innovation or even threaten a company's survival (Burgelman, 1994; Fredrickson and Mitchell, 1984; Hart, 1992; Maniak and Midler, 2014). In a comprehensive exploratory interview-based study Blichfeldt and Eskerod (2008) point out that companies typically have a plethora of 'under-the-radar' projects not managed or considered within project portfolio management frameworks. Project portfolio management is not only a structured and rational top-down driven process, but also 'can be viewed as negotiation and bargaining and as structural reconfiguration' (Martinsuo, 2013, p. 794) where project portfolios are not only deliberate but also emergent and affected by unplanned changes. Similarly Christiansen and Varnes (2009) observe that senior project portfolio managers do not necessarily follow defined procedures and rules but that their actions are also driven by observation of others, the organizational context and learning. Moreover, based on two case studies Jerbrant and Gustavsson (2013) report that project portfolio managers are moving away from formal procedures and are improvising in order to increase their 'action space'. Kester et al. (2011) provide further evidence that politics and intuition also play a role in project portfolio decision-making processes.

Acknowledging the existence of emergence, the question arises as to how emergence in a project portfolio affects strategy and ultimately success. Previous research has identified three 
phenomena, which represent examples of emergent strategies within multi-project landscapes: autonomous strategic behavior, bootlegging, and lineage management.

Burgelman (1983) identified autonomous strategic behavior as a source for strategic projects that are out of the organization's current strategic scope when initiated. Furthermore, he proposes that strategy may follow autonomous strategic behavior when the middlemanagers make sense out of these initiatives and manipulate the strategic context accordingly. More explicitly, Mirabeau and Maguire (2014) explored several autonomous strategic projects that have led to emergent strategies by mobilizing support for change and altering the strategic and structural context (Mirabeau and Maguire, 2014).

Bootlegging describes secretly organized projects initiated from the bottom-up, ignoring management directives, but often providing beneficial outcomes for organizations (Augsdorfer, 2005).

Another perspective on emerging strategies in multi-project environments is offered by Midler (2013) who describes the emergence of a strategy through cross-project learning based on a longitudinal case study. Multiproject lineage management is the term used to describe the dialectic process between strategy formulation and implementation through project sequencing observed in the study (Maniak and Midler, 2014). Furthermore, Midler and Silberzahn (2008) highlight that the agility offered by lineage management is a key success factor for a firm.

These three examples highlight the relevance and the positive impact that emerging elements in project portfolios can have on the organization's strategy. As Artto et al. (2004) stated, strategic renewal is enhanced by important emergent elements in the connection between projects and portfolio-level strategy processes.

Based on extant research on the impact projects have on the firm's strategy we conclude that, 1) strategies are to some extent emergent and to some extent deliberate, 2) projects in the 
portfolio can represent antecedents of emergent strategies, and 3) project portfolio management can facilitate the positive effect of emerging elements.

Thus, project portfolios can be both means for the implementation of intended strategies and sources of emergent strategies. We hypothesize that project portfolio management can provide valuable information regarding the need for strategic change and reveal strategic investment needs and opportunities. We refer to this information function as emerging strategy recognition and propose that it contributes to project portfolio success by providing the sensing mechanism to recognize and respond to emerging patterns.

\section{Hypothesis 2: Emerging strategy recognition is positively related to project} portfolio success.

We have detailed the role of portfolio management in the nexus between deliberate and emergent strategies in two ways: First, portfolio management integrates the firm's strategy with the project portfolio and aims to align the currently pursued strategy with the intended strategy. Second, it provides impetus for the adaptation and renewal of the intended strategy. Hypotheses 1 and 2 proposed that deliberate strategy implementation and emerging strategy recognition have the potential to improve success. Beyond their individual performance effect, we argue that there is a complementary effect; a superadditive effect such that an increase in either aspect amplifies the benefits of the other aspect. Following studies that highlight the benefits of managing both the deliberate and emergent elements concurrently (Burgelman, 1991; Hart, 1992; Hutchison-Krupat and Kavadias, 2015; Smeds et al., 2003) we propose a positive interaction between deliberate strategy implementation and emerging strategy recognition. 
Hypothesis 3: Deliberate strategy implementation and emerging strategy recognition are complementary in their effect on project portfolio success, i.e. there is a positive interaction effect.

The degree of external turbulence is an important contextual factor to consider when exploring the two roles of project portfolio management. Stable long-term strategies facilitate deliberate strategy implementation and provide long-term orientation for the project portfolio (Cooper and Kleinschmidt, 1995). However, long-term strategies require long-term predictions about market-related and technological developments. The more a firm's market and applied technologies are subject to high turbulence, the less accurate these long-term predictions will be and the more often strategies need to be revised. Likewise, Goold and Quinn (1990) propose that strategic controls that aim to implement intended strategies are most valuable in an environment marked by low turbulence. They argue that in highly turbulent environments the levels of effort required for monitoring the validity of strategy and the impact of environmental changes will be too high in relation to the potential benefits. In the same vein, Mintzberg and Waters (1985, p. 258) argued that for a strategy to be perfectly deliberate " $[t]$ he environment $[\ldots]$ must have been either perfectly predictable, totally benign, or else under the full control of the organization."

On the other side, emerging strategy recognition refers to the revealing of unplanned and unforeseen events. Such events are much more likely to occur in a turbulent environment. Furthermore, emerging strategy recognition represents a sensing capability that can enable organizations to detect and respond to changes in the environment (Teece, 2007; Teece et al., 1997). Similarly, the benefits of adaptability and responsiveness are dependent on the environment. Loch (2000) shows that radically new product development projects benefit from a less structured approach than incremental development projects. Especially in a turbulent environment, creativity and flexibility are required for successful strategies because 
they are less deliberate and irrevocable but emerging and evolutionary (Mintzberg and Waters, 1985).

Hence, we propose that in highly turbulent environments the merits of deliberate strategy implementation will be diminished or even offset by the effort to monitor and re-align the induced strategy while the relationship between emerging strategy recognition and project portfolio success is stronger.

Hypothesis 4a: The relationship between deliberate strategy implementation and project portfolio success is moderated by external turbulence such that the relationship is stronger in environments of low turbulence.

Hypothesis 4b: The relationship between emerging strategy recognition and project portfolio success is moderated by external turbulence such that the relationship is stronger in environments of high turbulence.

\subsection{Strategic control at the portfolio management level}

Band and Scanlan (1995) claimed that in order to be effective, strategic control 'needs to be pitched at a level which is sufficient to capture the full range of threats, opportunities and contingencies which might bear upon an organization's strategic choices' (Band and Scanlan, 1995, p. 106). We argue that the project portfolio management is the ideal level in the organization to facilitate effective strategic control as it is directly involved in implementing the intended strategy and includes capabilities to monitor and analyze the progress of its projects so that deviations or unexpected events can be detected. Therefore, the project portfolio perspective facilitates the implementation of strategic control functions that validate strategic assumptions (premise control) and scrutinize the pursued strategy (implementation control) (Muralidharan, 1997; Schreyögg and Steinmann, 1987). We build on previous research (Ittner and Larcker, 1997) and propose that strategic control is 
positively related to strategy implementation in terms of project portfolio success. In the following section we argue that strategic control is an antecedent to both deliberate strategy implementation and emerging strategy recognition, which in turn mediate the effect of strategic control on project portfolio success.

\subsection{Strategic control and deliberate strategy implementation}

Scrutinizing the strategy content and monitoring its underlying assumptions fosters the understanding of the strategy from the portfolio management perspective. A quantitative study by Kock and Gemünden (2016) reports a positive relationship between strategic clarity and decision-making clarity in portfolio management. Moreover, Schreyögg and Steinmann (1987) state that implementation control refers to questions about whether or not strategic projects should be continued. Such 'stop-or-go' decisions foster the alignment of the portfolio with the strategy in two ways: by ensuring that ongoing projects remain aligned with corporate strategy and strategic goals, and by terminating projects and unlocking additional resources that can then be allocated to more strategically aligned projects. In particular, this capability to terminate projects has been identified as a key success factor for strategic fit (Unger et al., 2012). We argue that strategic control contributes to deliberate strategy implementation by fostering the clarity of the strategy and facilitating the project prioritization, re-prioritization and termination decisions that keep the project portfolio aligned with the strategy.

Hypothesis 5: Strategic control is positively related to deliberate strategy implementation. 


\subsection{Strategic control and emerging strategy recognition}

Strategic controls, especially interactive strategic controls, include mechanisms to 'stimulate organizational learning and the emergence of new ideas and strategies' (Simons, 2013, p. 7). Such controls can reverse the relationship between strategy formulation and implementation by enabling organizations to quickly adapt to emergent strategies (Osborn, 1998). Emerging strategy recognition is enhanced by identifying changing conditions or unforeseen events (through premise control and strategic surveillance) and by disclosing emerging strategies or unfolding patterns of action (through implementation control). These strategic control activities provide the mechanisms for the disclosure of information that may influence strategic change.

Hypothesis 6: Strategic control is positively related to emerging strategy recognition.

By proposing that strategic control fosters deliberate strategy implementation and emerging strategy recognition, which in turn are antecedents of project portfolio success, we provide detail for the concept of the performance effect of strategic control that has been controversially discussed in previous research (Goold and Quinn, 1990; Ittner and Larcker, 1997). We suggest that the performance effect of strategic control may be explained by its influence on deliberate strategy implementation and emerging strategy recognition.

Hypothesis 7a: Deliberate strategy implementation mediates the relationship between strategic control and project portfolio success.

Hypothesis 7b: Emerging strategy recognition mediates the relationship between strategic control and project portfolio success. 


\section{Methodology}

\subsection{Sample}

A cross-industry sample of medium to large firms in Germany is used to test the proposed framework. Our object of analysis is the project portfolio of a firm or a business unit in case of large firms. For each portfolio we contacted two key informants - a decision maker and a coordinator. Decision maker informants were senior managers with decision authority over the portfolio in deciding on initiation, termination, or reprioritization of projects. Coordinator informants were middle managers in charge of actively managing the portfolio, such as portfolio managers, department managers, or project management organization heads. For hypotheses testing, we use the decision maker assessment of project portfolio success and environmental turbulence, and the coordinator assessment for the remaining variables. This two-informant approach allowed the integration of information from different perspectives and hierarchies within each firm and reduces the likelihood of common method bias (Podsakoff et al., 2003).

We received 189 decision maker questionnaires and 195 coordinator questionnaires from 200 firms (response rate of 19.7\%), resulting in 184 matched dyads with data from both types of informants. In order to test for non-response bias we compared the 25 percent early and late respondents using a t-test on all study variables and found no significant differences. Two observations were removed from analysis due to missing data. The 182 firms representing the final sample (response rate of 17.9\%) represent diverse industries (26\% automotive, $18 \%$ electronics/IT, $16 \%$ finance, $11 \%$ construction and utility, $8 \%$ health care, $7 \%$ logistics, $5 \%$ pharmaceuticals/chemicals, $9 \%$ others). Firm size varies across the sample with $32 \%$ having less than 500 employees, $29 \%$ between 500 and 2000 employees, and 39 $\%$ with more than 2,000 employees. Portfolio budget was less than 20 million $€$ in $37 \%$, 
between 20 and 100 million $€$ in $39 \%$, and higher than 100 million $€$ in $24 \%$ of the portfolios.

\subsection{Measurement}

We use multi-item scales for the constructs, which are anchored from 1, "strongly disagree", to 7, "strongly agree". Scales were operationalized based on existing literature and pretested with 12 representatives from academia and industry to assure face validity of constructs, improve item wording, and remove ambiguity. We validated the scales using principal components factor analysis (PCFA) and confirmatory factor analysis (CFA) (Ahire and Devaraj, 2001). We follow the guidelines of $\mathrm{Hu}$ and Bentler (1998) to evaluate structural equation models. They suggest a Comparative Fit Index (CFI) of 0.95 for good and of 0.90 for acceptable fit, and a Standardized Root Mean Squared Residual (SRMSR) and a Root Mean Squared Error of Approximation (RMSEA) below 0.08 for acceptable fit. 
Table 1. Confirmatory Factor Analysis for Project Portfolio Success

\begin{tabular}{lll}
\hline Construct & & loading \\
Dimension & Description & \\
Item & & \\
\hline
\end{tabular}

Project Portfolio Success ( $2^{\text {nd }}$ order construct)

Strategic Implementation success (Cronbach's Alpha $\alpha=0.85) \quad 0.78$

$\begin{array}{ll}\text { The project portfolio is consistently aligned with the future of the company. } & 0.81\end{array}$

$\begin{array}{ll}\text { The corporate strategy is implemented ideally through our project portfolio. } & 0.92\end{array}$

$\begin{array}{lr}\text { Resource allocation to projects reflects our strategic objectives. } & 0.78\end{array}$

$\begin{array}{ll}\text { The implementation of the strategy is considered a great success in the organization. } & 0.78\end{array}$

Future Preparedness $(\alpha=0.88) \quad 0.66$

We sufficiently develop new technologies and/or competences in our projects. $\quad 0.70$

With our projects we are a step ahead of our competition with new products, technologies, or services. 0.90

The projects enable us to shape the future of our industry. $\quad 0.74$

Portfolio Balance (Cronbach's Alpha $\alpha=0.85) \quad 0.68$

There is a good balance in our project portfolio ...

$\begin{array}{ll}\ldots \text {... between new and old areas of application. } & 0.82\end{array}$

$\begin{array}{lr}\text {... between new and existing technologies. } & 0.89\end{array}$

$\begin{array}{lr}\ldots \text { of project risks. } & 0.60\end{array}$

$\begin{array}{lr}\text { Average Product Success }(\alpha=0.88) & 0.69\end{array}$

Please assess the average success of completed projects:

$\begin{array}{ll}\text { Our products achieve the target costs defined in the project. } & 0.57\end{array}$

$\begin{array}{ll}\text { Our products achieve the planned market goals (e.g., market share). } & 0.64\end{array}$

Our products achieve the planned profitability goals (e.g., ROI). 0.94

$\begin{array}{ll}\text { Our products achieve the planned amortization period. } & 0.89\end{array}$

$\begin{array}{ll}\text { Synergy Exploitation }(\alpha=0.88) & 0.70\end{array}$

During the project execution, development synergies (e.g. shared use of modules, platforms, technologies 0.83

etc.) between projects are rigorously exploited

After project completion, exploitation synergies (e.g. shared marketing/sales channels, infrastructure, etc.) 0.85
between projects are rigorously exploited.

0.66

We hardly ever have double work or redundant development.

$\chi^{2}=214.40(d f=114 ; p<0.00) ; R M S E A=0.071 ; S R M R=0.068 ; C F I=0.94$.

The dependent variable project portfolio success is measured as a five-dimensional second-order construct using dimensions and their items from existing literature (Beringer et al., 2013; Cooper et al., 2001; Jonas et al., 2013; Kock et al., 2016; Voss and Kock, 2013): strategic implementation success (4 items), future preparedness ( 3 items), portfolio balance (3 items), average product success (4 items), and synergy exploitation (3). PCFA showed that all items load highly on their respective dimensions with no cross-loadings above 0.30 . The CFA confirms the second-order structure in that all dimensions load highly on the overall construct 
project portfolio success and the model fit is acceptable. The results and item wordings are shown in table 1 . The coordinator informant also assessed project portfolio success. Although we do not use these data for hypothesis testing, we used the information for further validation. The coordinator responses resulted in the same factor structure with similar loadings and fit. Both assessments are highly correlated $(\mathrm{r}=0.57)$, which gives strong confidence in the validity of our performance measure.

Table 2. CFA results for independent, mediator, and moderator variables

\begin{tabular}{llr}
\hline $\begin{array}{l}\text { Construct } \\
\text { Item }\end{array}$ & Description & loading \\
\hline
\end{tabular}

Strategic control $(\alpha=0.90)$

We frequently review ...

$\begin{array}{ll}\ldots \text {... the feasibility of portfolio strategy based on information acquired in projects. } & 0.87\end{array}$

$\begin{array}{ll}\text {... the validity of the premises defined within strategic planning. } & 0.90\end{array}$

... whether the strategy of the project portfolio is further justified in the light of changed conditions. $\quad 0.86$

$\begin{array}{ll}\text { Based on the information gained in the projects we deliberately challenge the portfolio strategy. } & 0.70\end{array}$

Deliberate strategy implementation $(\alpha=0.88)$

$\begin{array}{ll}\text { We put down the general guidelines for the portfolio via our strategic planning. } & 0.83\end{array}$

Portfolio planning and strategic planning are closely linked with each other in our company. 0.92

$\begin{array}{ll}\text { The goals of our project portfolio are derived from our company's goals. } & 0.77\end{array}$

Emerging strategy recognition $(\alpha=0.83)$

$\begin{array}{lr}\text { Through our project portfolio analyses we obtain valuable impulses for our strategy. } & 0.73\end{array}$

$\begin{array}{ll}\text { Through our project portfolio analyses we discover major new investment needs. } & 0.84\end{array}$

$\begin{array}{ll}\text { Through our project portfolio analyses we discover new business opportunities. } & 0.83\end{array}$

Environmental turbulence $(\alpha=0.84)$

$\begin{array}{ll}\text { The technology in our industry is changing rapidly. } & 0.87\end{array}$

$\begin{array}{ll}\text { There are frequent technological breakthroughs in our industry. } & 0.91\end{array}$

$\begin{array}{lr}\text { Technological changes provide big opportunities in our industry. } & 0.70\end{array}$

$\begin{array}{ll}\text { In our industry, it is difficult to predict how customers' needs and requirements will evolve. } & 0.43\end{array}$

$\begin{array}{ll}\text { In our kind of business, customers' product preferences change quite a bit over time. } & 0.54\end{array}$

$\begin{array}{lr}\text { In our industry, it is difficult to forecast competitive actions. } & 0.60\end{array}$

$\chi^{2}=167.06(d f=97 ; p<0.00) ; R M S E A=0.064 ; S R M R=0.071 ; C F I=0.96$.

Deliberate strategy implementation was measured as a three-item construct evaluating the degree to which the strategic planning process forms the basic conditions for the portfolio and how closely strategic and portfolio planning are linked to each other. The items were based on related constructs in the literature (Meskendahl, 2010). Emerging strategy recognition was 
measured by three items evaluating in how far portfolio analyses lead to new opportunities that were not visible during strategic planning. Strategic Control was measured with four items adapted from Schreyögg and Steinmann (1987) and Preble (1992). Environmental turbulence included three technology and three market turbulence items taken from Sethi and Iqbal (2008). A PCFA showed that all items loaded on their respective constructs with no cross-loadings higher than 0.30 . The results of the CFA are displayed in table 2 along with the item wording.

Finally, we control for several variables that may affect our model. Firm size and portfolio budget size might affect portfolio success (Jonas et al., 2013). Firm size is measured as the natural logarithm of the number of employees of the firm or business unit. Portfolio budget is measured as natural logarithm of the overall budget of the portfolio (measured in millions of Euros). Furthermore, we control for the innovativeness of the portfolio, which has been shown to affect performance (Talke et al., 2011). Portfolio innovativeness (Cronbach's Alpha $=0.84)$ is measured as the average technological innovativeness of projects in the portfolio with three items taken from previous literature (Kock et al., 2011; Talke et al., 2011). Finally, we control for portfolio management formalization $($ Alpha $=0.93)$ that we measure with four items taken from Teller et al. (2012). Portfolio management formalization is an indicator of the maturity of portfolio processes and should therefore be controlled for (Kopmann et al., 2015).

Correlations and descriptives for all variables are shown in table 3. Strategic control is strongly correlated to deliberate strategy implementation and emerging strategy recognition, which could constitute a threat to discriminant validity. However, the CFA shows that these constructs are discriminant. When pair-wise correlations between the constructs are constrained to one, the model significantly worsens (Delta $\chi^{2}=99.35(\mathrm{p}<0.00)$ and Delta $\chi^{2}=$ 113.37 ( $\mathrm{p}<0.00)$ respectively). Furthermore, the average variance extracted (AVE) is higher 
than 0.64 for all three constructs. The square root of the AVE is consequently higher than the highest correlation between constructs, which indicates discriminant validity (Fornell and Larcker, 1981).

Table 3. Correlations and Descriptives

\begin{tabular}{|c|c|c|c|c|c|c|c|c|c|c|c|}
\hline & Variable & Mean & $\begin{array}{l}\text { Std. } \\
\text { dev }\end{array}$ & (1) & (2) & (3) & (4) & $(5)$ & (6) & (7) & (8) \\
\hline (1) & Project Portfolio Success & 4.57 & 0.80 & 1.00 & & & & & & & \\
\hline (2) & $\begin{array}{l}\text { Environmental } \\
\text { Turbulence }\end{array}$ & 4.01 & 1.07 & 0.09 & 1.00 & & & & & & \\
\hline (3) & Firm Size (ln) & 7.03 & 1.91 & 0.09 & 0.04 & 1.00 & & & & & \\
\hline (4) & Portfolio Budget (ln) & 3.39 & 1.65 & 0.06 & 0.08 & 0.36 & 1.00 & & & & \\
\hline (5) & Portfolio Innovativeness & 4.16 & 1.25 & 0.26 & 0.44 & 0.02 & 0.13 & 1.00 & & & \\
\hline (6) & $\begin{array}{l}\text { Formalization of } \\
\text { Portfolio Management }\end{array}$ & 4.71 & 1.75 & 0.32 & 0.03 & 0.16 & 0.14 & -0.03 & 1.00 & & \\
\hline (7) & Strategic Control & 3.84 & 1.41 & 0.34 & -0.04 & -0.02 & 0.01 & 0.04 & 0.39 & 1.00 & \\
\hline (8) & $\begin{array}{l}\text { Deliberate strategy } \\
\text { implementation }\end{array}$ & 4.67 & 1.43 & 0.38 & -0.05 & 0.01 & 0.03 & 0.00 & 0.35 & 0.68 & 1.00 \\
\hline (9) & $\begin{array}{l}\text { Emerging strategy } \\
\text { recognition }\end{array}$ & 3.61 & 1.25 & 0.36 & 0.05 & 0.02 & 0.02 & 0.12 & 0.29 & 0.60 & 0.44 \\
\hline
\end{tabular}




\section{Results}

We use ordinary least squares regression in order to test the hypotheses. The first model in table 4 contains the direct effects of all control and moderator variables as well as strategic control on project portfolio success. Model 2 introduces the two mediators in order to test hypotheses 1 and 2. Deliberate strategy implementation $(b=0.13, p<0.01)$ and emerging strategy recognition $(\mathrm{b}=0.13, \mathrm{p}<0.01)$ both have positive and significant coefficients. Hypothesis 1 and 2 are therefore supported by the data. Model 3 tests the complementary effect of deliberate strategy implementation and emerging strategy recognition. Following Aiken, West and Reno (1991) we introduce the product-term between the centered variables and evaluate whether the explained variance significantly increases. Model 3 shows that the interaction of deliberate strategy implementation and emerging strategy recognition is positive and significant $(b=0.06, p<0.01)$, which is in support of hypothesis 3 . Model 4 tests

the moderation effects of external turbulence. As expected in hypothesis $4 \mathrm{a}$ we find a negative moderation effect with deliberate strategy implementation $(b=-0.08, p<0.05)$. However, we cannot find any significant moderating effects with emerging strategy recognition; therefore hypothesis $4 \mathrm{~b}$ is not supported by the data. 
Table 4. Regression Results

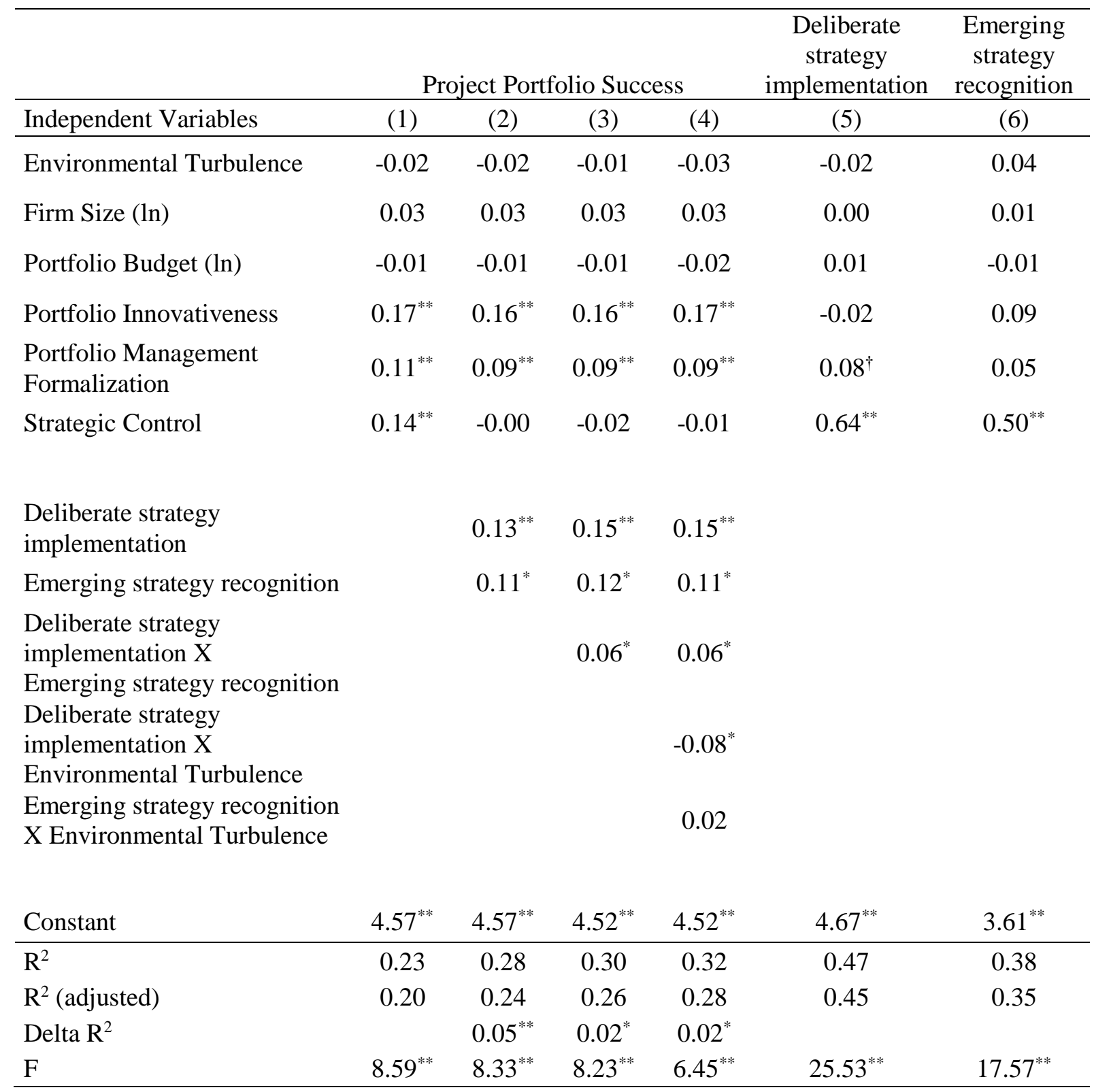

Hierarchical OLS regression; $n=182$; mean-centered variables; unstandardized regression coefficients are reported; $\uparrow \mathrm{p}<0.10 ; * \mathrm{p}<0.05 ; * * \mathrm{p}<0.01$ (two-sided).

To visualize the moderation effect we use a marginal plot to show the strength and significance for all possible values of the moderator variable (Brambor et al., 2006). The solid line in Figure 2 represents the effect of deliberate strategy implementation on project portfolio success over the range of external turbulence. The dashed lines represent $95 \%$ confidence intervals. Figure 2 shows that deliberate strategy implementation only has a 
positive and significant effect on project portfolio success if external turbulence is below 4.3 (mean is 4.01). Higher turbulence diminishes the positive effect of deliberate strategy implementation on success.

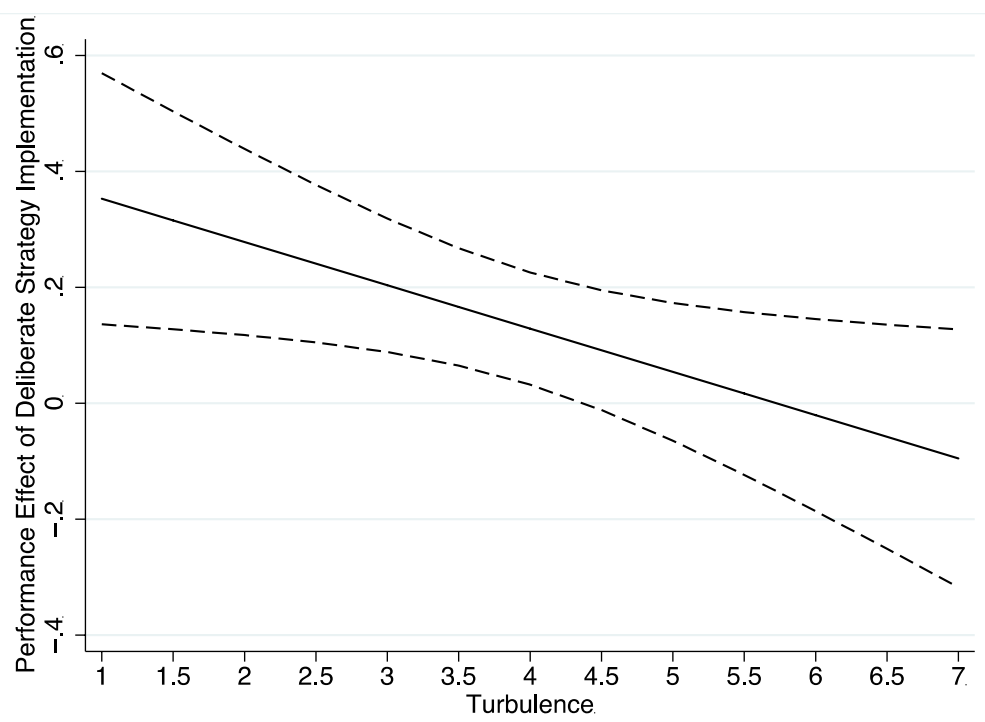

\section{Figure 2. Marginal effects of deliberate strategy implementation depending on}

environmental turbulence (the dashed lines represent 95 percent confidence intervals)

Model 5 tests the relationship between strategic control and deliberate strategy implementation and finds a positive and significant effect $(b=0.64, p<0.01)$, which supports hypothesis 5. Similarly, model 6 supports hypothesis 6 in showing a positive and significant effect between strategic control and emerging strategy recognition $(b=0.50, p<0.01)$. We furthermore test whether the effect of strategic control on project portfolio success is mediated by deliberate strategy implementation and emerging strategy recognition. We follow the procedure suggested by Zhao et al. (2010) and calculate the significance of the indirect effects using bootstrapping with 1000 replications. Both indirect effects of strategic control through deliberate strategy implementation $\left(b_{\text {ind }}=0.09, p<0.01\right)$ and emerging strategy recognition $\left(b_{\text {ind }}=0.06, p<0.05\right)$ are positive and significant, supporting hypotheses $7 \mathrm{a}$ and $7 \mathrm{~b}$. 
Since the direct effect of strategic control on project portfolio success is not significant when controlling for the mediator variables, the mediation is an indirect-only mediation (Zhao et al., 2010).

\section{Discussion}

This empirical study contributes to the recent calls to broaden the understanding of emergent strategies and explore how organizations can manage a strategy formation process that is driven by both emergence and intention (Hamel, 2009; Vaara and Whittington, 2012). Our focus on strategic control at the project portfolio management level provides detail of a specific management practice that plays a distinctive role in the managing deliberate strategy while also facilitating 'planned emergence'.

The findings show that strategic control at the project portfolio level contributes to success by supporting the implementation of both deliberate and emergent strategies through deliberate strategy implementation and emerging strategy recognition activities. The effects are complementary in that both activities increase the positive influence of the other on the success of the project portfolio. Finally, a moderation analysis shows that the influence of deliberate strategy implementation on project portfolio success is reduced under high environmental turbulence.

\subsection{Theoretical Implications}

This research provides the first quantitative study from a project portfolio perspective to complement earlier studies that explore the phenomenon of emergent strategies and related strategic management practices (Burgelman, 1994; Chari et al., 2014; Mirabeau and Maguire, 2014; Thomas and Ambrosini, 2015). The results of this study contribute to the literature in three primary ways. 
First, we introduce the project portfolio management perspective into the discussion and provide insights on the management of emergent strategies from that perspective. Beyond its role in the realization of deliberate strategy, we show that portfolio management is an active player in shaping strategy by disclosing strategic opportunities and thus providing an important impetus for strategy formulation in response to environmental conditions. The result that top-down operationalization of strategy (i.e. deliberate strategy implementation) becomes less relevant for success under conditions of high environmental turbulence further highlights the relationship portfolio management's role in shaping strategy in response to change. By illustrating how strategic controls at the portfolio level provide mechanisms for sensing and reconfiguring through emerging strategy recognition, and revealing that the level of environmental turbulence affects the role of deliberate strategy implementation activities, the results of this study support previous studies that position project portfolio management as a dynamic capability (Killen and Hunt, 2010; Killen et al., 2007; Killen et al., 2012; Petit and Hobbs, 2010). The findings also provide support for arguments that a dual process approach could be at play where the deliberate strategy implementation approaches operate in a relatively stable fashion, while emerging strategy recognition aspects cater for dynamism (Schreyögg and Kliesch-Eberl, 2007).

Second, this study reveals the connections between the concepts of emerging strategies and strategic control in the context of project portfolio management. The literature suggests that strategic control enables organizations to cope with the challenges of emergent strategies (Osborn, 1998; Simons, 2013; van Veen-Dirks and Wijn, 2002), which are more likely to occur in highly turbulent environments (Mintzberg and McHugh, 1985). However, in their conceptual work Goold and Quinn (1990) propose that strategic controls are most valuable in an environment marked by low turbulence. Our findings address these contrasting views by separately investigating aspects of deliberate strategy implementation and emerging strategy 
recognition. We find that deliberate strategy implementation is moderated by environmental turbulence, and for this aspect Goold and Quinn's propositions apply: strategic controls for deliberate strategy implementation are more effective when turbulence is low. Contrary to our expectations, we did not observe an effect on the emerging strategy recognition aspect of strategic control from differing levels of environmental turbulence.

Finally, and paradoxically, an 'emergent' finding from this study is the insights it offers on methods for 'planned emergence'. The concept of 'planned emergence' is compelling due to the tension that exists between rigid strategic planning and control that may lead to an irrelevant strategy in dynamic environments, and too little control that could lead to the realization of a fragmented and uncoordinated strategy. From one perspective, 'emergent strategies' could be defined as outside formal planning and control processes - and therefore not able to be 'planned'. However, our findings that strategic controls can play a positive role in enhancing emerging strategy recognition, and in turn in enhancing project portfolio success, suggest that there are ways that emergent strategies can be nurtured through formal means. Our findings align with research by Grant (2003) by revealing how emergent strategy processes complement deliberate top-down strategy processes to enhance success, especially in turbulent environments. Interest in 'planned emergence' is growing from a number of perspectives including strategy, foresight, and manufacturing (see for example e Cunha et al., 2006; Idoko and MacKay, 2016; Kim et al., 2014; Sanderson et al., 2015; van der Duin and den Hartigh, 2009). We offer early findings that enhance understanding about whether and how emergence can be planned, contributing to what we believe will be an important research theme for improving organizational approaches and outcomes in dynamic environments. 


\subsection{Managerial Implications}

For practitioners, this study offers insights on the importance of emergent strategies for organizational success and provides guidance for proactive approaches to sense and respond to these emergent elements while also managing the intended strategy. The findings show how strategic control activities at the project portfolio level can facilitate both deliberate and emerging strategy and provide benefits at the interface between strategy formulation and implementation. These results support the integration of project portfolio management into the strategic formation process - not only as an instrument to implement the strategy, but also as a valuable source for strategic renewal and change.

\subsection{Limitations and Future Research}

This study gives rise to future research opportunities, some of which stem from its limitations. First, there are limitations in the perspectives explored in this study. We investigated the interface between strategy formulation and implementation at the project portfolio level using responses from senior and middle managers. Future studies could investigate the performance effect of emerging strategy recognition in more depth to illuminate the mechanisms involved. Future research may also benefit from the inclusion of additional perspectives such as the views from top management to reveal the mechanism by which emerging strategy recognition affects strategy formulation. Similarly, it would be interesting to include the bottom-up perspective of project managers or team members. In particular, employee voice behavior, which is a form of extra-role behavior that focuses on changing the current situation, processes, or procedures, has been repeatedly argued to positively affect organizational decision-making (Bashshur and Oc, 2015). Since voice behavior has only been scarcely investigated in project management research (Ekrot et al., 2016), and studies on its organizational outcomes are rare in general (Bashshur and Oc, 
2015), this research field could fruitfully contribute to emerging strategy formation. Although we did not set out to look for 'planned emergence' in this study, our findings contribute to the growing interest in this concept, and provide support for further research in this area. Finally, future studies that take a multi-level, longitudinal, and micro-foundational perspective would provide deeper insights into how strategies actually emerge (Barney and Felin, 2013) and could build on recent qualitative studies conducted from such a perspective (Maniak and Midler, 2014; Midler, 2013; Mirabeau and Maguire, 2014).

\section{References}

Ahire, S.L., Devaraj, S., 2001. An empirical comparison of statistical construct validation approaches. IEEE Transactions on Engineering Management, 48, 319-329.

Aiken, L.S., West, S.G., Reno, R.R., 1991. Multiple regression: testing and interpreting interactions. Sage Publications, Newbury Park, Calif.

Archer, N.P., Ghasemzadeh, F., 2004. Project portfolio selection and management, in: Morris, P.W.G., Pinto, J.K. (Eds.), The Wiley guide to managing projects. Wiley Online Library, pp. 237255.

Artto, K., Dietrich, P., Nurminen, M., 2004. Strategy Implementation by Projects, Innovations: Project Management Research 2004.

Atkinson, H., 2006. Strategy implementation: A role for the balanced scorecard? Management Decision, 44, 1441-1460.

Augsdorfer, P., 2005. Bootlegging and path dependency. Research Policy, 34, 1-11.

Band, D.C., Scanlan, G., 1995. Strategic control through core competencies. Long Range Planning, $28,102-114$.

Barney, J., Felin, T., 2013. What Are Microfoundations? Academy of Management Perspectives, 27, 138-155.

Bashshur, M.R., Oc, B., 2015. When voice matters - A multilevel review of the impact of voice in organizations. Journal of Management, 41, 1530-1554.

Benko, C., McFarlan, F.W., 2003. Connecting the dots: Aligning projects with objectives in unpredictable times. Harvard Business Press.

Beringer, C., Jonas, D., Kock, A., 2013. Behavior of internal stakeholders in project portfolio management and its impact on success. International Journal of Project Management, 31, 830-846.

Bititci, U., Garengo, P., Dörfler, V., Nudurupati, S., 2012. Performance Measurement: Challenges for Tomorrow*. International Journal of Management Reviews, 14, 305-327.

Blichfeldt, B.S., Eskerod, P., 2008. Project portfolio management - There's more to it than what management enacts. International Journal of Project Management, 26, 357-365.

Blomquist, T., Müller, R., 2006. Practices, roles, and responsibilities of middle managers in program and portfolio management. Project Management Journal, 37, 52-66. 
Bower, J.L., Gilbert, C.G., 2005. From resource allocation to strategy. Oxford University Press Oxford, UK.

Brambor, T., Clark, W.R., Golder, M., 2006. Understanding interaction models: Improving empirical analyses. Political Analysis, 14.

Burgelman, R.A., 1983. A model of the interaction of strategic behavior, corporate context, and the concept of strategy. Academy of Management Review, 8, 61-70.

Burgelman, R.A., 1991. Intraorganizational ecology of strategy making and organizational adaptation: Theory and field research. Organization Science, 2, 239-262.

Burgelman, R.A., 1994. Fading Memories: A Process Theory of Strategic Business Exit in Dynamic Environments. Administrative Science Quarterly, 39, 24-56.

Chari, S., Katsikeas, C.S., Balabanis, G., Robson, M.J., 2014. Emergent Marketing Strategies and Performance: The Effects of Market Uncertainty and Strategic Feedback Systems. British Journal of Management, 25, 145-165.

Christiansen, J.K., Varnes, C.J., 2009. Formal Rules in Product Development: Sensemaking of Structured Approaches*. Journal of Product Innovation Management, 26, 502-519.

Cooper, R.G., Edgett, S.J., Kleinschmidt, E.J., 1999. New product portfolio management: practices and performance. Journal of Product Innovation Management, 16, 333-351.

Cooper, R.G., Edgett, S.J., Kleinschmidt, E.J., 2001. Portfolio management for new products, 2nd ed. Perseus Pub., Cambridge, MA.

Cooper, R.G., Kleinschmidt, E.J., 1995. Benchmarking the firm's critical success factors in new product development. Journal of Product Innovation Management, 12, 374-391.

Dietrich, P., Lehtonen, P., 2005. Successful management of strategic intentions through multiple projects-Reflections from empirical study. International Journal of Project Management, 23, 386391.

e Cunha, M.P., Palma, P., da Costa, N.G., 2006. Fear of foresight: Knowledge and ignorance in organizational foresight. Futures, 38, 942-955.

Ekrot, B., Rank, J., Gemünden, H.G., 2016. Antecedents of project managers' voice behavior: The moderating effect of organization-based self-esteem and affective organizational commitment. International Journal of Project Management, 34, 1028-1042.

Englund, R.L., Graham, R.J., 1999. From experience: linking projects to strategy. Journal of Product Innovation Management, 16, 52-64.

Engwall, M., Jerbrant, A., 2003. The resource allocation syndrome: The prime challenge of multiproject management? International Journal of Project Management, 21, 403-409.

Fornell, C., Larcker, D.F., 1981. Evaluating Structural Equation Models with Unobservable Variables and Measurement Error. Journal of Marketing Research, 18, 39-50.

Fredrickson, J.W., Mitchell, T.R., 1984. Strategic Decision-Processes - Comprehensiveness and Performance in an Industry with an unstable Environment. Academy of Management Journal, 27, 399-423.

Goold, M., Quinn, J.J., 1990. The Paradox of Strategic Controls. Strategic Management Journal, 11, 43-57.

Grant, R.M., 2003. Strategic planning in a turbulent environment: Evidence from the oil majors. Strategic Management Journal, 24, 491-571.

Hamel, G., 2009. Moon shots for management. Harvard Business Review, 87, 91-98.

Hart, S.L., 1992. An Integrative Framework for Strategy-Making Processes. The Academy of Management Review, 17, 327-351. 
Hodgkinson, G.P., Whittington, R., Johnson, G., Schwarz, M., 2006. The Role of Strategy Workshops in Strategy Development Processes: Formality, Communication, Co-ordination and Inclusion. Long Range Planning, 39, 479-479.

Hrebiniak, L.G., 2006. Obstacles to Effective Strategy Implementation. Organizational Dynamics, 35, $12-31$.

Hu, L.T., Bentler, P.M., 1998. Fit indices in covariance structure modeling: Sensitivity to underparameterized model misspecification. PSYCHOLOGICAL METHODS, 3, 424-453.

Hutchison-Krupat, J., Kavadias, S., 2015. Strategic Resource Allocation: Top-Down, Bottom-Up, and the Value of Strategic Buckets. Management Science, 61, 391-412.

Hutzschenreuter, T., Kleindienst, I., 2006. Strategy-Process Research: What Have We Learned and What Is Still to Be Explored. Journal of Management, 32, 673-721.

Idoko, O., MacKay, R.B., 2016. How strategy tools as activation devices perform strategy theory. Academy of Management Proceedings, 2016.

Ittner, C.D., Larcker, D.F., 1997. Quality strategy, strategic control systems, and organizational performance. Accounting, Organizations and Society, 22, 293-314.

Jerbrant, A., Gustavsson, T.K., 2013. Managing project portfolios: balancing flexibility and structure by improvising. International Journal of Managing Projects in Business, 6, 152-172.

Johnson, G., Scholes, K., Whittington, R., 2008. Exploring Corporate Strategy. Financial Times Prentice Hall.

Johnson, L.K., 2004. Execute Your Strategy -- Without Killing It. Harvard Management Update, 9, 36.

Jonas, D., Kock, A., Gemünden, H.G., 2013. Predicting Project Portfolio Success by Measuring Management Quality-A Longitudinal Study. IEEE Transactions on Engineering Management, $60,215-226$.

Kester, L., Griffin, A., Hultink, E.J., Lauche, K., 2011. Exploring Portfolio Decision-Making Processes. Journal of Product Innovation Management, 28, 641-661.

Killen, C.P., Hunt, R.A., 2010. Dynamic capability through project portfolio management in service and manufacturing industries. International Journal of Managing Projects in Business, 3, 157-169.

Killen, C.P., Hunt, R.A., Kleinschmidt, E.J., 2007. Dynamic capabilities: Innovation project portfolio management, Managing our Intellectual and Social Capital: Australian and New Zealand Academy of Management (ANZAM), Sydney Australia.

Killen, C.P., Hunt, R.A., Kleinschmidt, E.J., 2008. Project portfolio management for product innovation. International Journal of Quality \& Reliability Management, 25, 24-38.

Killen, C.P., Jugdev, K., Drouin, N., Petit, Y., 2012. Advancing project and portfolio management research: Applying strategic management theories. International Journal of Project Management, 30, 525-538.

Kim, Y.H., Sting, F.J., Loch, C.H., 2014. Top-down, bottom-up, or both? Toward an integrative perspective on operations strategy formation. Journal of Operations Management, 32, 462-474.

Kock, A., Gemünden, H.G., 2016. Antecedents to Decision-making Quality and Agility in Innovation Portfolio Management. Journal of Product Innovation Management 10.1111/jpim.12336.

Kock, A., Gemünden, H.G., Salomo, S., Schultz, C., 2011. The Mixed Blessings of Technological Innovativeness for the Commercial Success of New Products. Journal of Product Innovation Management, 28, 28-43.

Kock, A., Heising, W., Gemünden, H.G., 2015. How Ideation Portfolio Management Influences Front-End Success. Journal of Product Innovation Management, 32, 539-555. 
Kock, A., Heising, W., Gemünden, H.G., 2016. A Contingency Approach on the Impact of Front-End Success on Project Portfolio Success. Project Management Journal, 47, 115-129.

Kopmann, J., Kock, A., Killen, C.P., Gemünden, H.G., 2015. Business Case Control in Project Portfolios - An Empirical Investigation of Performance Consequences and Moderating Effects. IEEE Transactions on Engineering Management, 62, 529-543.

Kürschner, S., Günther, T., 2012. Design parameters of the strategic planning process and organizational performance-a quantitative analysis of empirical research. Journal für Betriebswirtschaft, 62, 5-44.

Levina, N., Su, N., 2008. Global Multisourcing Strategy: The Emergence of a Supplier Portfolio in Services Offshoring. Decision Sciences, 39, 541-570.

Loch, C., 2000. Tailoring product development to strategy: Case of a European technology manufacturer. European Management Journal, 18, 246.

Maniak, R., Midler, C., 2014. Multiproject lineage management: Bridging project management and design-based innovation strategy. International Journal of Project Management, 32, 1146-1156.

Mankins, M.C., Steele, R., 2005. Turning Great Strategy into Great Performance. Harvard Business Review, 83, 64-72.

Martinsuo, M., 2013. Project portfolio management in practice and in context. International Journal of Project Management, 31, 794-803.

McKiernan, P., Morris, C., 1994. Strategic Planning and Financial Performance in UK SMEs: Does Formality Matter? British Journal of Management, 5, S31-S41.

Meissner, P., 2014. A process-based perspective on strategic planning: the role of alternative generation and information integration. Business Research, 7, 105-124.

Meskendahl, S., 2010. The influence of business strategy on project portfolio management and its success - A conceptual framework. International Journal of Project Management, 28, 807-817.

Midler, C., 2013. Implementing a Low-End Disruption Strategy Through Multiproject Lineage Management: The Logan Case. Project Management Journal, 44, 24-35.

Midler, C., Silberzahn, P., 2008. Managing robust development process for high-tech startups through multi-project learning: The case of two European start-ups. International Journal of Project Management, 26, 479-486.

Mintzberg, H., 1978. Patterns in Strategy Formation. Management Science, 24, 934-948.

Mintzberg, H., 1990. The design school: Reconsidering the basic premises of strategic management. Strategic Management Journal, 11, 171-195.

Mintzberg, H., McHugh, A., 1985. Strategy formation in an adhocracy. Administrative Science Quarterly, 160-197.

Mintzberg, H., Waters, J.A., 1985. Of Strategies, Deliberate and Emergent. Strategic Management Journal, 6, 257-272.

Mirabeau, L., Maguire, S., 2014. From autonomous strategic behavior to emergent strategy. Strategic Management Journal, 35, 1202-1229.

Morgan, M., Levitt, R.E., Malek, W.A., 2008. Executing Your Strategy: How to Break It Down and Get It Down. Harvard Business School Publishing India Pvt. Limited.

Morris, P.W.G., Jamieson, A., 2005. Moving from Corporate Strategy to Project Strategy. Project Management Journal, 36, 5-18.

Müller, R., Martinsuo, M., Blomquist, T., 2008. Project Portfolio Control and Portfolio Management Performance in Different Contexts. Project Management Journal, 39, $28-42$. 
Muralidharan, R., 1997. Strategic control for fast-moving markets: updating the strategy and monitoring performance. Long Range Planning, 30, 64-73.

Noda, T., Bower, J.L., 1996. Strategy making as iterated processes of resource allocation. Strategic Management Journal, 17, 159-192.

Osborn, C.S., 1998. Systems for Sustainable Organizations: Emergent Strategies, Interactive Controls and Semi-formal Information. Journal of Management Studies, 35, 481-509.

Parnell, J.A., Dent, E.B., O'Regan, N., Hughes, T., 2012. Managing Performance in a Volatile Environment: Contrasting Perspectives on Luck and Causality. British Journal of Management, 23, S104-S118.

Petit, Y., 2012. Project portfolios in dynamic environments: Organizing for uncertainty. International Journal of Project Management, 30, 539-553.

Petit, Y., Hobbs, B., 2010. Project portfolios in dynamic environments: Sources of uncertainty and sensing mechanisms. Project Management Journal, 41, 46-58.

Podsakoff, P.M., MacKenzie, S.B., Lee, J.-Y., Podsakoff, N.P., 2003. Common Method Biases in Behavioral Research: A Critical Review of the Literature and Recommended Remedies. Journal of Applied Psychology, 88, 879-903.

Poskela, J., Dietrich, P., Berg, P., Artto, K.A., Lehtonen, T., 2005. Integration of Strategic Level and Operative Level Front-end Innovation Activities, Portland International Conference on Management of Engineering and Technology. PICMET, Portland, Oregon, pp. 1-22.

Poskela, J., Martinsuo, M., 2009. Management control and strategic renewal in the front end of innovation. Journal of Product Innovation Management, 26, 671-684.

Preble, J.F., 1992. Towards a comprehensive system of strategic control. Journal of Management Studies, 29, 391-408.

Raes, A.M.L., Heijltjes, M.G., Glunk, U., Roe, R.A., 2011. THE INTERFACE OF THE TOP MANAGEMENT TEAM AND MIDDLE MANAGERS: A PROCESS MODEL. Academy of Management Review, 36, 102-126.

Regner, P., 2003. Strategy Creation in the Periphery: Inductive versus Deductive Strategy Making. Journal of Management Studies, 40, 57-82.

Sanderson, D., Ratchev, S., Kelly, E., Busquets, D., Pitt, J., 2015. Self-Organising Electronic Institutions and Flexible Manufacturing Systems. IFAC-PapersOnLine, 48, 2071-2076.

Schreyögg, G., Kliesch-Eberl, M., 2007. How dynamic can organizational capabilities be? Towards a dual-process model of capability dynamization. Strategic Management Journal, 28, 913-933.

Schreyögg, G., Steinmann, H., 1987. Strategic control: a new perspective. Academy of Management Review, 91-103.

Sethi, R., Iqbal, Z., 2008. Stage-Gate Controls, Learning Failure, and Adverse Effect on Novel New Products. Journal of Marketing, 72, 118-134.

Shenhar, A.J., Dvir, D., Levy, O., Maltz, A.C., 2001. Project success: a multidimensional strategic concept. Long range planning, 34, 699-725.

Simons, R., 2013. Levers of Control: How Managers Use Innovative Control Systems to Drive Strategic Renewal. Harvard Business Review Press.

Smeds, R., Haho, P., Alvesalo, J., 2003. Bottom-up or top-down? Evolutionary change management in NPD processes. International Journal of Technology Management, 26, 887.

Talke, K., Salomo, S., Kock, A., 2011. Top management team diversity and strategic innovation orientation: the relationship and consequences for innovativeness and performance. Journal of Product Innovation Management, 28, 819-832. 
Teece, D.J., 2007. Explicating dynamic capabilities: the nature and microfoundations of (sustainable) enterprise performance. Strategic Management Journal, 28, 1319-1319.

Teece, D.J., Pisano, G., Shuen, A., 1997. Dynamic capabilities and strategic management. Strategic Management Journal, 18, 509-533.

Teller, J., Unger, B.N., Kock, A., Gemünden, H.G., 2012. Formalization of project portfolio management: The moderating role of project portfolio complexity. International Journal of Project Management, 30, 596-607.

Thomas, L., Ambrosini, V., 2015. Materializing Strategy: The Role of Comprehensiveness and Management Controls in Strategy Formation in Volatile Environments. British Journal of Management, 26, S105-S124.

Thomas, L.G., D'Aveni, R., 2009. The changing nature of competition in the US manufacturing sector, 1950-2002. Strategic Organization, 7, 387-431.

Unger, B.N., Kock, A., Gemünden, H.G., Jonas, D., 2012. Enforcing strategic fit of project portfolios by project termination: An empirical study on senior management involvement. International Journal of Project Management, 30, 675-685.

Vaara, E., Whittington, R., 2012. Strategy-as-practice: taking social practices seriously. The Academy of Management Annals, 6, 285-336.

van der Duin, P.A., den Hartigh, E., 2009. Keeping the balance: exploring the link of futures research with innovation and strategy processes. Technology Analysis \& Strategic Management, 21, 333351.

van Veen-Dirks, P., Wijn, M., 2002. Strategic control: meshing critical success factors with the balanced scorecard. Long Range Planning, 35, 407-427.

Voss, M., Kock, A., 2013. Impact of relationship value on project portfolio success - Investigating the moderating effects of portfolio characteristics and external turbulence. International Journal of Project Management, 31, 847-861.

Whittington, R., Yakis-Douglas, B., Ahn, K., Cailluet, L., 2016. Strategic Planners in More Turbulent Times: The Changing Job Characteristics of Strategy Professionals, 1960-2003. Long Range Planning.

Zhao, X., Lynch, J.G., Chen, Q., 2010. Reconsidering Baron and Kenny: Myths and Truths about Mediation Analysis. Journal of Consumer Research, 37, 197-206. 